\title{
Male mating behaviour in relation to female sexual swellings, socio-sexual behaviour and hormonal changes in wild Barbary macaques
}

\author{
Christopher Young a,*, Bonaventura Majolo ${ }^{\text {b }}$, Michael Heistermann ${ }^{c}$, Oliver Schülke ${ }^{d}$, Julia Ostner ${ }^{a}$ \\ a Primate Social Evolution Group, Courant Research Centre Evolution of Social Behaviour, Georg-August University Göttingen, Kellnerweg 6, 37077, Germany \\ b School of Psychology, University of Lincoln, Brayford Pool, Lincoln, LN6 7TS, UK \\ c Reproductive Biology Unit, German Primate Center, Göttingen, Kellnerweg 4, 37077, Germany \\ d Courant Research Centre Evolution of Social Behaviour, Georg-August University Göttingen, Kellnerweg 6, 37077, Germany
}

\section{A R T I C L E I N F O}

\section{Article history:}

Received 17 July 2012

Revised 2 November 2012

Accepted 3 November 2012

Available online 10 November 2012

\section{Keywords:}

Barbary macaque

Macaca sylvanus

Post-conception mating

Male reproductive strategies

Sexual swellings

Progestogens

Paternity confusion

\begin{abstract}
A B S T R A C T
In many cercopithecine primates females display probabilistic cues of fertility to indicate the periovulatory period to males. These cues may include female behaviour, acoustic signals, and morphological signs such as the anogenital swelling. However, the extent to which males can utilise this information varies between species. We describe male sexual behaviour in relation to changes in anogenital swelling size, timing of ovulation and female socio-sexual behaviour in wild Barbary macaques (Macaca sylvanus). We further compare male sexual behaviour during conception and post-conception cycles to evaluate if males differentiate between these qualitatively different cycle types. Our results show that during conception cycles male mating behaviour was concentrated around the fertile phase implying that males inferred information from more than swelling size alone. Male mating frequency increased in line with female socio-sexual behaviour, namely female presenting and the frequency of copulations with copulation calls. Most strikingly our results show that males invested equally in mating during fertile and non-fertile, i.e. post-conception, maximum swelling phases. Whether post-conception swellings were merely a result of changes in hormone concentrations during pregnancy or part of a female reproductive strategy remains elusive. In sum, this study adds to the body of research on the evolution of female sexual signals and how males may infer information from these cues.
\end{abstract}

(c) 2012 Elsevier Inc. All rights reserved.

\section{Introduction}

In most mammalian species females are only sexually receptive around the time of ovulation, the period when conception is possible (McCarthy and Becker, 2002). Females may indicate this period by behavioural, visual, olfactory, vocal or tactile cues to males (Lisk et al., 1983; Rasmussen and Schulte, 1998; Sherman, 1989; Swaisgood et al., 2002; Westlin, 1996). Many female primates differ from this general mammalian trend by having a prolonged period of receptivity which extends beyond the fertile phase (Aujard et al., 1998; Bielert and Anderson, 1985; Carnegie et al., 2005; Deschner et al., 2004; Engelhardt et al., 2004; for review see Hrdy and Whitten, 1987) and even into gestation (Engelhardt et al., 2007; Fürtbauer et al., 2011; Lu et al., 2012; Ostner et al., 2006). It has been proposed that females use this extended receptivity to both confuse and concentrate mating activity in order to reduce the future risk of infanticide by males (van Schaik et al., 2000). In this study, we investigate male sexual behaviour in relation to changes in female anogenital swelling size, timing

\footnotetext{
* Corresponding author. Fax: +49551399637.

E-mail address: christopher.young@zentr.uni-goettingen.de (C. Young).
}

of ovulation and female socio-sexual behaviour in Barbary macaques (Macaca sylvanus), a species with prominent sexual swellings.

Anogenital sexual swellings may function as part of a female strategy to balance paternity confusion and concentration in primates living in multi-male multi-female groups (van Schaik et al., 2000). Sexual swellings may act as probabilistic visual cues to males of the timing of ovulation, reaching maximum size around ovulation (Brauch et al., 2007; Deschner et al., 2003; Higham et al., 2008b; Reichert et al., 2002; for review see Dixson, 1998; Nunn, 1999; Nunn and Altizer, 2004). By signalling to males the most likely time of ovulation, females enable dominant males to concentrate their efforts around this most important period, while still confusing paternity and mating with multiple males at smaller swelling stages when ovulation is less likely but still possible (Nunn et al., 2001). Across several anthropoid taxa such as baboons (Higham et al., 2009), mandrills (Setchell et al., 2005), macaques (Engelhardt et al., 2004; Higham et al., 2012; O'Neill et al., 2004), and apes (Barelli et al., 2008; Deschner et al., 2003; Emery and Whitten, 2003) ovulation occurs during maximum swelling (but see Shelmidine et al., 2007). However, whether males hone further information from more subtle changes in swelling size (Deschner et al., 2004; Higham et al., 2009), olfactory cues around ovulation (Cerda-Molina et al., 2006) or female 
proceptive behaviour (Aujard et al., 1998; Engelhardt et al., 2005; Wallen et al., 1984; Zehr et al., 1998, 2000) to infer when to concentrate mating varies between species.

In macaques, female proceptive behaviour has been shown to vary during the reproductive cycle and may thus be used by males as a cue to discern the fertile phase. Several studies have shown that the expression of female proceptive behaviours, such as approaching, soliciting and presenting to males is strongly related to changes in oestrogen levels and increase in frequency around the fertile phase (Aujard et al., 1998; Wallen et al., 1984; Zehr et al., 1998, 2000). Further research has shown that female sexual behaviour and motivation may be influenced by the social environment; in rhesus macaques, M. mulatta, for example, social group composition (differing male and female composition) influenced how closely related copulation rates were to female reproductive state (Wallen, 2001). The social and environmental conditions of primates can therefore influence sexual behaviour so research under natural conditions can build on previous studies under a more controlled environment.

Mating activity in numerous primate species continues into gestation and a few species even exhibit additional sexual swellings during this post-conception, i.e. non-fertile, period, which may serve as an additional mechanism of females to further confuse paternity and decrease the risk of infanticide (van Schaik et al., 2000, 2004). One of these species is the Barbary macaque, where females show exaggerated swellings both during fertile as well as post-conception phases (Brauch et al., 2007; Küster and Paul, 1984; Möhle et al., 2005). Both swelling types follow similar underlying endocrine changes, particularly an increase in the oestrogen to progestogen ratio (E/P ratio) coinciding with the occurrence of the maximum swelling (Möhle et al., 2005). To date few studies have looked into the function of post-conception swellings and male sexual behaviour in relation to these additional swelling phases in this or other species (Engelhardt et al., 2007; Gordon et al., 1991; Gust, 1994).

The aim of this study was two-fold. We firstly aimed to investigate how male Barbary macaques change their sexual behaviours in relation to females' timing of ovulation, changes in swelling size and sociosexual behaviour. Secondly, we examined whether males differentiate between qualitatively different swelling types by comparing the frequency of male behaviour during conception and post-conception swelling phases. In order to provide the context for these analyses we describe how female sexual swelling size is related to her hormonally assessed fertile phase.

\section{Methods}

\section{Study site and subjects}

Data were collected from two wild, unprovisioned groups ("Green" (Gn) and "Scarlet" (Sc)) of Barbary macaques living in a deciduous cedar and oak forest in the Middle-Atlas Mountains of Morocco $\left(33^{\circ} 24^{\prime} 9 \mathrm{~N}-005^{\circ} 12^{\prime} 9 \mathrm{~W}\right)$. The groups consisted of 7-9 adult males and 8 adult females (Gn) and 6 males and 8 females (Sc), respectively. Data were collected on the Green group from Oct. 2009-Apr. 2011, data here represent the mating seasons Oct.-Dec. 2009 (Gn09) and Sept.-Dec. 2010 (Gn10). Data on the Scarlet group were collected from Jul. 2010-Apr. 2011, data here represent the mating season Sept.-Dec. 2010 (Sc10). The mating season was defined as the first to last observed ejaculatory copulation during either focal or ad libitum data collection. This study adhered to the legal requirements of Morocco, Germany and Great Britain.

\section{Behavioural data collection and construction of the hierarchy}

Behavioural data were collected by $\mathrm{CY}$ and 5 field assistants from 0700 to $1900 \mathrm{~h}$. All adult males in both groups were subject to continuous focal animal observation of social and sexual behaviour (Altmann,
1974), yielding a total of 820 focal hours during the mating seasons (341 h Gn09, 304 h Gn10 and 175 h Sc10). Data were collected using handheld HP iPAQ 114 series pocket PCs loaded with Pendragon Forms Version 5.1 (ㄷ Pendragon Software Cooperation, U.S.A.). Focal sampling was randomised within groups and one 40-min focal session per male was recorded per observation day so as to give an even number of focal sessions per individual.

Ejaculatory copulations were recorded and indicated by the occurrence of an ejaculatory pause in pelvic thrusts (Küster and Paul, 1984) and/or the presence of fresh ejaculate around the female's genital area after the copulation. Male inspection (tactile, olfactory or visual) of female's anogenital region as well as female "presenting" behaviour (female presents anogenital region to male; "presenting", Brauch et al., 2007), was also recorded. During ejaculatory copulations the following female socio-sexual behaviours were recorded: the female reaches back to the male during copulation ("reach back", Deag, 1974), female looks back at the male during copulation ("look back"), and female vocalizations during copulation ("copulation call”, Semple, 1998).

Agonistic interactions or conflicts were defined by the occurrence of aggressive (bite, chase, slap, grab, stare, open-mouth, head-bob and charge) and/or submissive behaviours (give-ground, make-room, flee, crouch submission). In total 1238 (Gn) and 195 (Sc) male-male dyadic conflicts were observed where a clear winner and loser of a conflict could be determined with no counter-aggression. Based on this, a winner-loser matrix was constructed and a male's dominance rank was assessed using corrected Normalized David's Scores (de Vries et al., 2006) to give a continuous measure of dominance. We used the "Steepness" package (Leiva and de Vries, 2011) in R 2.14.0 (R Development Core Team, 2011) based on a matrix of proportions of wins calculated for each dyad.

\section{Faecal sample collection, hormone analysis and definition of the fertile phase}

Faecal samples of all adult females of the study groups were collected within $15 \mathrm{~min}$ of defecation to assess timing of ovulation ( $N=1066$ samples). Samples were collected for each female when the anogenital swelling began to increase in size towards maximum swelling, throughout the maximum swelling period and 10 days after detumescence. Samples were homogenized and a 3-5 g piece was placed in a polypropylene vial, which was in-turn placed in an ice bag and kept cold until samples were transferred to a freezer at $-20{ }^{\circ} \mathrm{C}$ at the end of the day. Samples were transferred in a frozen state to the German Primate Centre for hormonal analysis. Samples were freeze-dried, pulverized and an aliquot of $0.05-0.08 \mathrm{~g}$ was extracted with $3 \mathrm{ml} 80 \%$ methanol in water according to the method reported by Heistermann et al. (1995). Extracts were analysed for concentrations of immunoreactive progestagen metabolites $(5 \alpha$ reduced-20-oxo pregnanes, 5-P-3OH) using a previously validated enzyme immunoassay (EIA) (Brauch et al., 2007; Heistermann et al., 2008; Möhle et al., 2005) and according to procedures previously described by Hodges et al. (1997). Intra- and inter-assay coefficients of variation, calculated from replicate determinations of high- and low-value quality controls, were $5.8 \%$ and $11.5 \%$ (high) and $8.8 \%$ and $13.9 \%$ (low), respectively.

For the two groups and three mating seasons we were able to analyse 23 cycles. However, analysis of behavioural data was restricted to those cycles in which the frequency of faecal sample collection was sufficiently high (sample gap of no greater than 3 days before postovulatory progestagen rise) to allow the estimation of the day of ovulation to an acceptable level of precision (see Dubuc et al., 2011; Heistermann et al., 2008). This gave a total 155 samples from 12 cycles from 10 different females for analysis. The fertile period was determined for each cycle, as previously described by Heistermann et al. (2008). Specifically, a defined rise in faecal 5-P-3OH levels above a threshold value (2 SDs above the preceding mean baseline level) was 
used to determine the most likely day of ovulation (Day 0). As in Brauch et al. (2007), we determined a two day window of the most likely days of ovulation, days -2 to -3 , due to the excretion time lag of faecal progesterone metabolites of $24-56 \mathrm{~h}$ for macaque species (Shideler et al., 1993). The fertile phase consisted of days -2 to -6 relative to the defined faecal 5-P-3OH rise, the 2 day ovulation window plus the preceding 3 days to account for sperm life span in the female reproductive tract (Behboodi et al., 1991; Wilcox et al., 1995). For each cycle, the 5 days before the fertile period were defined as the "pre-fertile" period and after as the "post-fertile" period.

\section{Classification of fertile and swelling periods}

Anogenital swelling size was assessed visually using the following approach. In the field swelling size was graded using a three point scale and adapted from the methods of Aujard et al. (1998) and Heistermann et al. (1996), with grade 1 indicating a female with no or minimal swelling or minimal size, grade 2 was given where a partial swelling was present and grade 3 was observed where a maximum swelling was present (tumescence, i.e. the swelling was at maximum size with no wrinkles, and there was protrusion of all genital structures, and this was the period of maximum turgidity).

The maximum swelling period lasted from the first to last consecutive days of a grade 3 swelling (the "maximum swelling" period). We used a combination of hormonal data and counting back from day of parturition $170 \pm 3.77$ days (gestation length: mean $\pm S D$, Young et al. unpubl. data) from the date of infant birth to estimate if the swelling period corresponded to a conception, pre-conception or post-conception cycle for each female where birth dates were available (20 of 22 females gave birth the following birth season).

\section{Probability of fertility}

We estimated the probability of ovulation for each day of the maximum swelling period $(T)$ by dividing the number of observed ovulations on each day of the maximum swelling by the maximum number of ovulatory cycles examined, following the methods of Deschner et al. (2003). We used the following formula:

$P(T=t)=\frac{n_{t}}{n}, t=1,2,3 \ldots$,

where $t$ is the specific day within the maximum swelling period, $n_{t}$ is the number of cycles in which ovulation occurred on day $t$, and $n$ is the overall number of ovulatory cycles. The 5 day fertile phase was determined as above.

To calculate a day specific probability of fertility we took the fertile phase for each cycle and assumed that the probability of fertilisation remains the same for all 5 days. For a day of the fertile phase a probability of fertilisation of 1 was assigned and days outside of this period were assigned 0 . On any given day of the maximum swelling period (f) the average likelihood of fertility was estimated, we summed the scores of probability of ovulation for day $f$ and the following 3 days. This probability is given by:

$P(X(f)=1)=\sum_{t=f}^{f+3} P(T=t)$

where $\{X(f)=1\}$ is the event of a fertile day and $P(T=t)$ from above.

\section{Statistical analysis}

We compared the maximum swelling period to the fertile phase for the 12 females for whom we had accurate hormonal data. We used a binomial test to examine how many maximum swelling days were also days of the fertile phase. To investigate temporal changes in male sexual behaviour we looked at behaviour around the fertile phase examining mean behavioural rates for the post-fertile phase, the fertile phase and both days -5 to -9 and days -10 to -14 with respect to the fertile phase (days -4 to 0 ). We compared the mean hourly ejaculatory copulation and inspection rates for each female during the pre-fertile, post-fertile and fertile periods using a Wilcoxon signed rank test. Female behaviours are either (copulation call, "look back" and "reach back") expressed as frequency of behaviours females expressed on a specific day relative to the number of copulations females engaged in that day, or (presenting) as the hourly rate per day. Temporal changes in female behaviours were compared using the same methods as for male sexual behaviours above.

Using a Generalized Linear Mixed Model (GLMM; Baayen, 2008) (model 1) we tested whether copulation rate was better predicted by days of the maximum swelling period or days of the fertile phase. Copulation rate was measured on the basis of the number of observed ejaculatory copulations per day and included as the dependent variable. Predictor variables were swelling and fertile phase day (was a given day of the mating season a day of maximum swelling or fertile phase period, respectively, 1/0). Fertile phase/maximum swelling day was set to 1 if the corresponding day was within the 5 day fertile or the maximum swelling period respectively and to 0 otherwise. Year, group and female ID were included as random effects and we controlled for effort (log-transformed) as an offset variable in the model (focal hours per day).

A second GLMM model (model 2) was used to examine how daily male copulation frequency was related to female sexual behaviours and different swelling stages. Copulation rate was measured on the basis of the number of observed ejaculatory copulations per day across all males in the group and included as the dependent variable. The first predictor variable was swelling stage (categorical, 3 levels). Level 1: non-maximum swelling (period 10 days before and after a maximum swelling), level 2: conception maximum swelling (period of maximum swelling during a conception cycle), level 3: post-conception maximum swelling (period of maximum swelling during a post-conception cycle). We also included as continuous predictor variables: the percentage of copulations including female copulation calls, reach backs or look backs as well as the hourly rate of female presenting on a given day. Year, group and female ID were included as random effects and we controlled for effort (log-transformed) as an offset variable in the model (focal hours per day). As the categorical variable swelling stage had three levels we reordered the variable using the "relevel" function so that "conception swelling period" became the reference variable and therefore all levels could be compared to each other.

We ran the GLMM's in R 2.14.0 (R Development Core Team, 2011) using the function lmer of the R package lme4 (Bates and Maechler, 2010). All GLMM's were fitted with Poisson error structure and log-link function and likelihood ratio tests were calculated using the $\mathrm{R}$ function anova. Significance of the individual fixed effects was determined based on the $X^{2}$ - and p-values provided by lmer. Assumptions for lack of over dispersion and multicollinearity were respected for the analyses.

To compare whether the duration of conception and postconception swelling periods differed we used a paired $t$-test. To examine the behavioural influence of post-conception swellings, we compared male sexual behaviours between maximum swelling periods of conception and post-conception swellings of ten females. Male sexual behaviour (ejaculatory copulations and inspection rates) and female presenting behaviour, expressed as mean behavioural rates per hour, was compared between the two types of swelling cycles using Wilcoxon signed rank tests.

Where appropriate, we report mean values \pm standard deviation (SD). All statistical analyses were carried out using R 2.14.0 software (R Development Core Team, 2011). The level of significance was set at $\alpha<0.05$. 


\section{Results}

\section{Probability of fertility}

There was a temporal correspondence between the maximum swelling period and the fertile phase for the 12 female cycles. Results indicated that a significant number of days (65\%) of the fertile phase fell within the maximum swelling period (binomial test, $x=39, N=60$, $\mathrm{p}<0.027$; Fig. 1). The probability of ovulation was highest on days -2 and $-4(0.167)$, relative to the last day of maximum tumescence (day 0), and slightly lower on day $-3(0.125)$ giving a peak period of ovulation probability on these 3 days (Fig. 2). The combined probability of ovulation across these 3 days was 0.46; however, ovulation could occur on any day from day -9 to +1 . Consequently, fertilisation was possible from days -13 to +3 and was most probable between days -2 and -6 reaching a peak on day -4 (0.625; Fig. 2 ).

\section{Male sexual behaviour around the fertile phase}

Mean hourly rates of male sexual behaviour during different periods of female fertility were examined comparing the fertile period with the pre-/post-fertile periods respectively. In separate tests rates of ejaculatory copulations as well as inspection rates were significantly higher in the fertile as well as the pre-fertile period compared to the postfertile period, while there was no difference between the pre-fertile and the fertile periods (Fig. 3). Ejaculatory copulation rates: pre-fertile vs. fertile: $V=63, p=0.064$; fertile vs. post-fertile: $V=75, p=0.002$; pre-fertile vs. post-fertile: $\mathrm{V}=47, \mathrm{p}=0.053$. Inspection rates: prefertile vs. fertile: $V=52, p=0.340$; fertile vs. post-fertile: $V=71$, $\mathrm{p}=0.010$; pre-fertile vs. post-fertile: $\mathrm{V}=12, \mathrm{p}=0.034, \mathrm{~N}=12$ for all tests.

A GLMM (model 1) revealed that male mating rate was predicted by days of the fertile period but not by days of the maximum swelling period (Table 1).

\section{Comparing the conception and post-conception maximum} swelling periods

The duration of the conception maximum swelling period (mean \pm $\mathrm{SD}=8.27 \pm 2.45$ days) was not significantly different from the maximum swelling post-conception period (mean $\pm S D=6.64 \pm 2.5$ days; $t$-test: $\mathrm{t}=1.54, \mathrm{df}=20, \mathrm{p}=0.14)$. Post-conception swellings occurred 25-30 days after detumescence of the conception swelling period and the vast majority of females (80\%) developed a post-conception swelling. No more than one post-conception swelling was observed for any female.

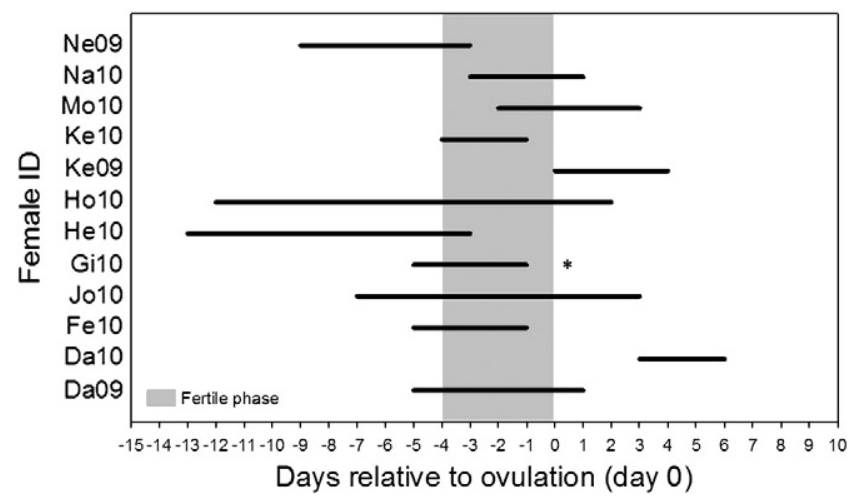

Fig. 1. Duration and timing of the maximum swelling periods relative to day of ovulation (day 0 ). Periods of maximum swelling for 10 females and 12 ovulatory cycles are each represented by horizontal lines. The shaded area represents the fertile window. The identity of each female is given along with the mating season year $(09=2009$, $10=2010)$. Non-conceptive cycles are indicated by an asterisk.

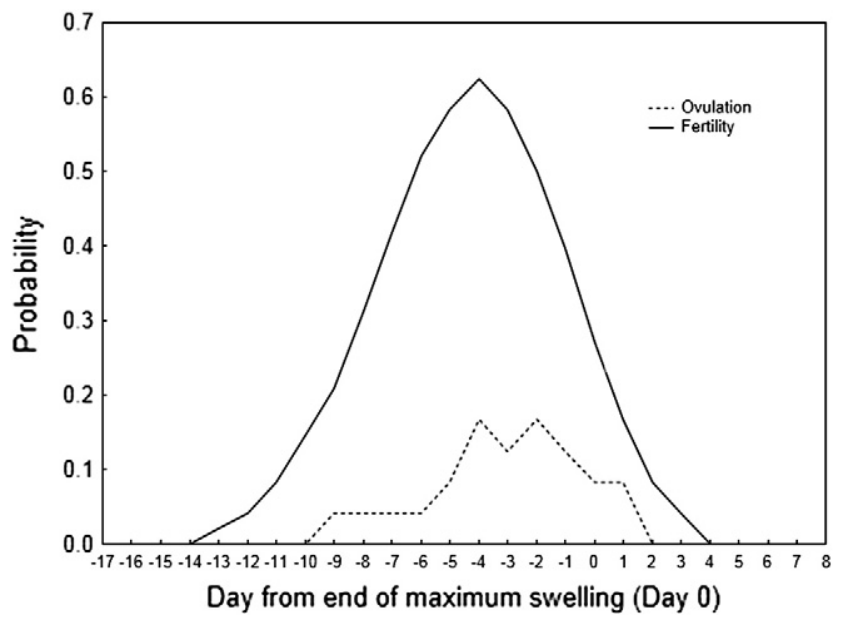

Fig. 2. Probability of ovulation (dashed line) and fertility (solid line) relative to the last day of maximum tumescence (day 0; see Methods section for details).

There was no significant difference in mean hourly frequency of male matings or inspections between the conception and postconception swelling periods (ejaculatory copulation rate: mean \pm $\mathrm{SD}=0.231 \pm 0.14$ (conception maximum swelling), $0.235 \pm 0.22$ (post-conception maximum swelling); $\mathrm{V}=32, \mathrm{p}=0.70$; inspection rate: mean $\pm \mathrm{SD}=0.553 \pm 0.22$ (conception maximum swelling), $0.702 \pm 0.51$ (post-conception maximum swelling); $\mathrm{V}=16, \mathrm{p}=0.28$, $\mathrm{N}=10$ for both tests, Fig. 4). The alpha males were no exception and did not concentrate their mating efforts to conceptive swelling phases (ejaculatory copulation rate: mean $\pm \mathrm{SD}=0.03 \pm 0.02$ versus $0.05 \pm 0.03$ during conception and post-conception maximum swelling phases, $\mathrm{V}=0, \mathrm{p}=0.37, \mathrm{~N}=3$ ). The mean hourly frequency of female presenting also did not differ significantly between the two swelling periods (mean $\pm S D=0.471 \pm 0.35$ (conception maximum swelling), $0.490 \pm 0.33$ (post-conception maximum swelling); $V=24$, $\mathrm{p}=0.77, \mathrm{~N}=10$ ).

\section{Male sexual behaviour in relation to female socio-sexual behaviour}

In the second GLMM (model 2) we examined how the males' copulation behaviour was related to a given female's swelling state, her conception status, and her socio-sexual behaviour on a given day. The copulations all group males engaged in were more frequent on days of maximum swelling size, no matter whether the female was fertile or already pregnant. The males also copulated more the more frequently a female presented and the higher the proportion of her copulations that were associated with copulation calls. The proportion of copulations that were associated with the more subtle female behaviours of looking back at the copulating male or reaching back to him were not related to the males' copulation rate (Table 2 ).

\section{Discussion}

Combining hormonal measurements with visual scoring of swelling sizes we found swellings to be a probabilistic indicator of fertility as the occurrence of ovulation was most likely during the maximum swelling period but the timing of ovulation within the swelling varied. Male copulation frequency was higher during maximum swelling periods than outside this period but mating rate was still better predicted by the hormonally assessed fertility than by swelling size, suggesting that more than the maximum swelling size alone was used by males to determine female attractivity. Male mating behaviour was additionally predicted by female socio-sexual behaviour, namely female presenting and the percentage of copulations with copulation calls, however, whether males use these behaviours or 

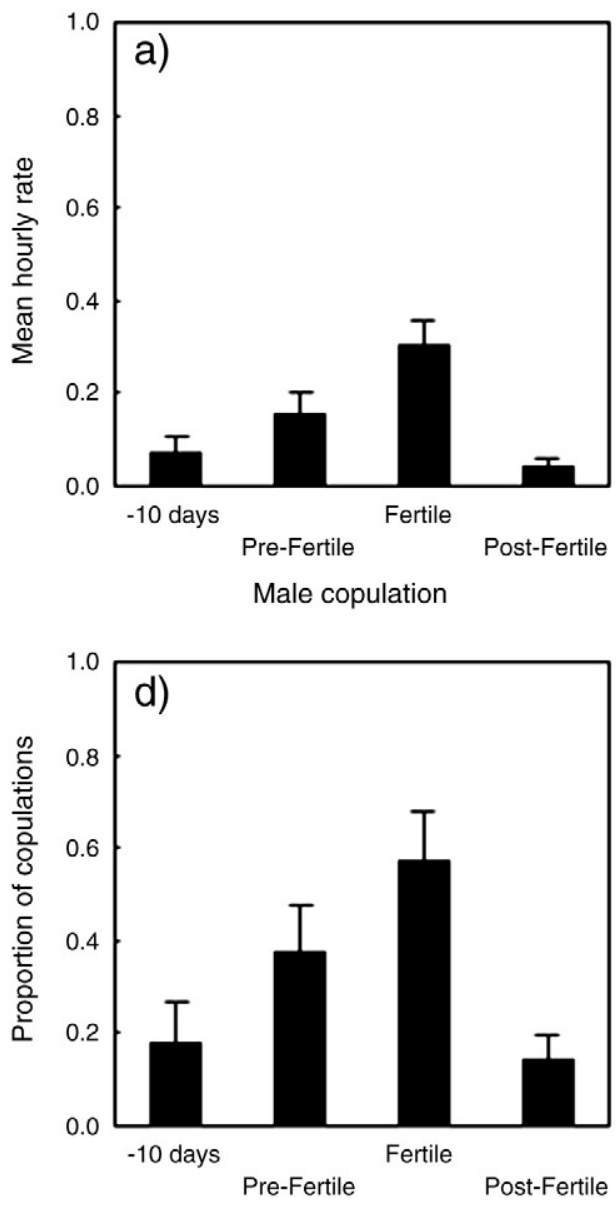

Female copulation call
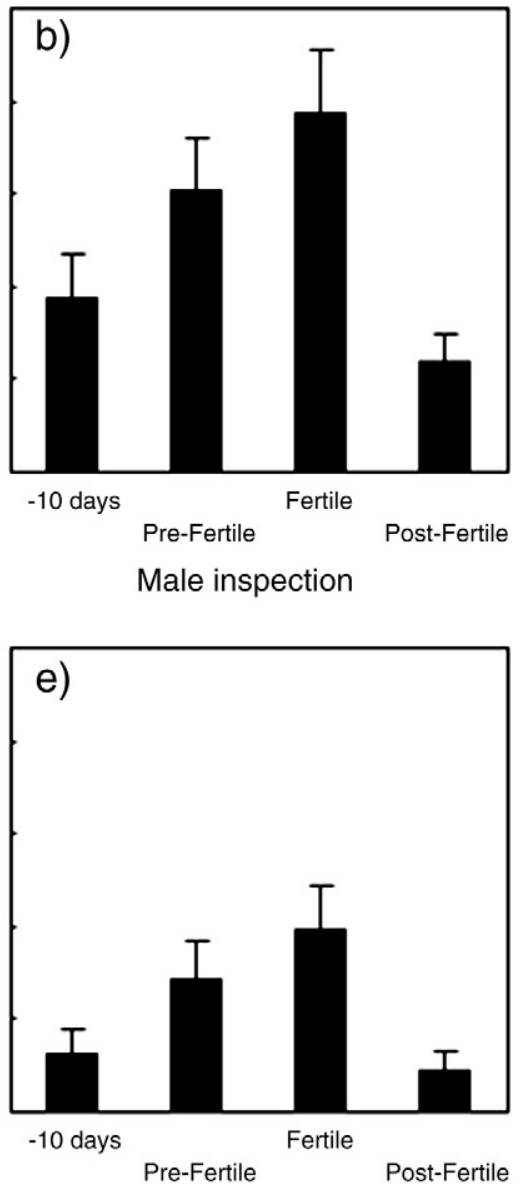

Female look back

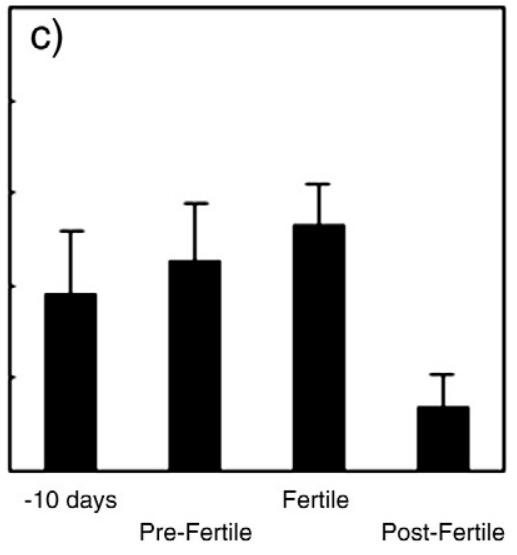

Female presenting

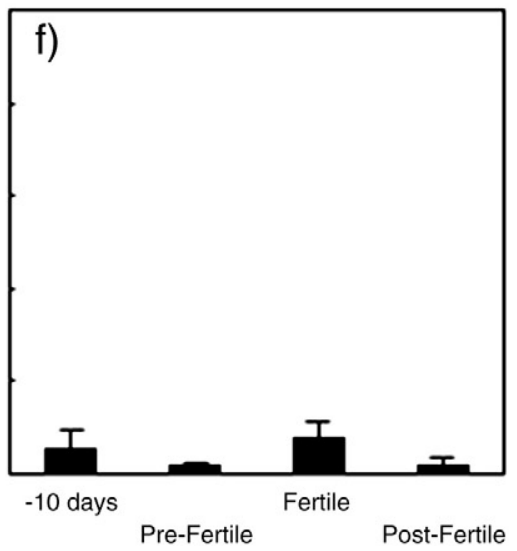

Female reach back

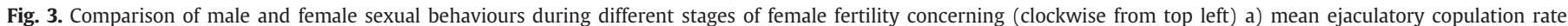

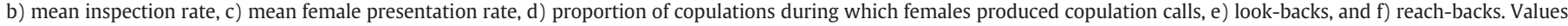
were averaged across all cycles $(\mathrm{N}=12)$ and represent the mean $\pm \mathrm{SEM}$.

additional information as cues to allocate their mating activity was beyond the scope of this study. Most strikingly, males engaged at equal rates in sexual behaviour during fertile and post-conception swelling stages, despite the fact that the mating during the latter by definition cannot lead to fertilisations and thus only carries costs for the male.

There was a temporal correspondence between maximum swelling size and fertility with the majority of maximum swelling days also being fertile days, i.e. days when ovulation was most likely. The actual day of ovulation did vary, however, within the maximum swelling period as has been shown in several other species (Deschner et al., 2003; Higham et al., 2008b; Reichert et al., 2002) including semi-free ranging Barbary macaques (Möhle et al., 2005). The probability of

Table 1

GLMM Poisson regression results for the relationship between male ejaculatory copulation rate on a given day and whither this is a day of the fertile phase (determined hormonally) or the maximal swelling period $(\mathrm{N}=628)$.

\begin{tabular}{lllll}
\hline Independent variable & GLMM estimate & SE & $Z$ & $\mathrm{P}(>|Z|)$ \\
\hline Intercept & -1.33 & 0.40 & -3.32 & $<0.001$ \\
Day of fertile phase & 1.494 & 0.20 & 7.603 & $<0.001$ \\
Day of maximal swelling period & 0.206 & 0.21 & 1.002 & 0.31
\end{tabular}

Random effects

Year estimated variance $\pm S D=0.16 \pm 0.16$

Group estimated variance $\pm \mathrm{SD}=0.07 \pm 0.26$

Female ID estimated variance $\pm S D=0.36 \pm 0.6$ fertility peaked 5 days before detumescence, which is consistent with chimpanzees (Deschner et al., 2003) and 1 day less than in baboons (Higham et al., 2008a). In addition to maximum swellings during conception, $80 \%$ of females also had a post-conception maximum swelling period, a finding very similar to that reported for

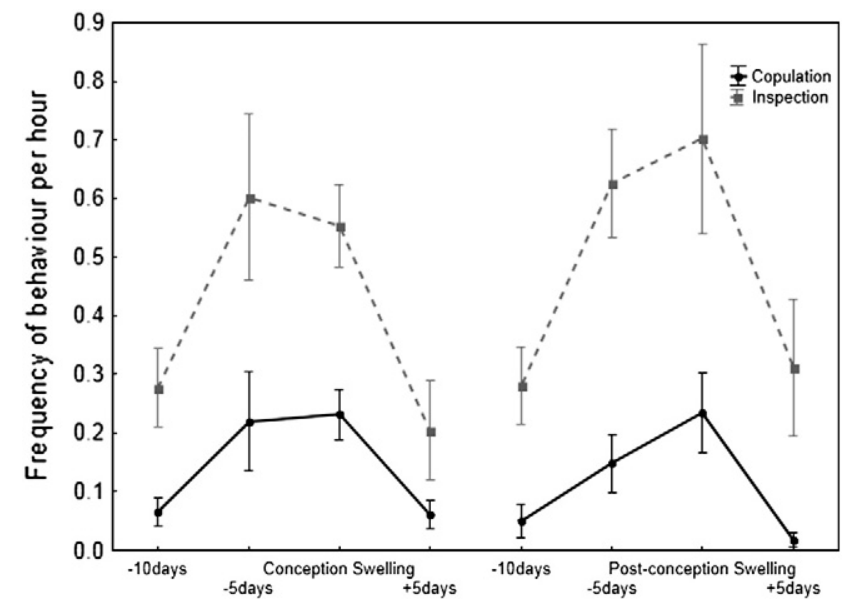

Fig. 4. Mean hourly rate of male copulations and inspections in relation to the different maximum swelling periods, as well as the 5 days after the swelling period ( +5 days) and days $1-5$ ( -5 days) and days $6-10$ ( -10 days) before the swelling period. Values were averaged across all cycles $(\mathrm{N}=10)$ and represent the mean $\pm \mathrm{SEM}$. 
Table 2

GLMM Poisson regression results for the relationship between male ejaculatory copulation rate on a given day and female sexual behaviours (female presentations per hour, percentage of copulations with copulation calls, look backs and reach backs) and different maximal swelling periods (conception maximal swelling, post-conception maximal swelling or the 10 days before and after a swelling period) $(\mathrm{N}=415)$.

\begin{tabular}{|c|c|c|c|c|}
\hline Independent variable & $\begin{array}{l}\text { GLMM } \\
\text { estimate }\end{array}$ & SE & $Z$ & $\mathrm{P}(>|Z|)$ \\
\hline Intercept & -3.35 & 0.31 & -10.704 & $<0.001$ \\
\hline $\begin{array}{l}\text { Conception max-swelling vs. post- } \\
\text { conception max-swelling }\end{array}$ & -0.24 & 0.18 & -1.329 & 0.184 \\
\hline $\begin{array}{l}\text { Conception max-swelling vs. } \\
\text { non-max-swelling }\end{array}$ & 0.61 & 0.16 & 3.908 & $<0.001$ \\
\hline $\begin{array}{l}\text { Post-conception max-swelling vs. } \\
\text { non-max-swelling }\end{array}$ & 0.36 & 0.17 & 2.208 & 0.03 \\
\hline Female presentations/h & 0.52 & 0.08 & 6.772 & $<0.001$ \\
\hline$\%$ Copulations with copulation call & 2.29 & 0.26 & 8.882 & $<0.001$ \\
\hline$\%$ Copulations with look back & 0.16 & 0.20 & 0.822 & 0.41 \\
\hline \% Copulations with reach back & -0.22 & 0.24 & -0.926 & 0.35 \\
\hline \multicolumn{5}{|l|}{ Random effects } \\
\hline \multicolumn{5}{|c|}{ Year estimated variance $\pm S D=0.00 \pm 0.00$} \\
\hline \multicolumn{5}{|c|}{ Group estimated variance $\pm S D=0.00 \pm 0.00$} \\
\hline \multicolumn{5}{|c|}{ Female ID estimated variance $\pm S D=0.61 \pm 0.78$} \\
\hline
\end{tabular}

semi-free ranging animals (Möhle et al., 2005). In macaques, maximum swelling size is preceded by endocrine changes with a decrease in progestogen levels and an increase in oestrogen levels and thus a significant rise in the E/P ratio which is similar during maximum swelling for both conception and post-conception periods (Engelhardt et al., 2007; Möhle et al., 2005). If males were to use the absolute swelling size or the underlying endocrine changes as a cue when to concentrate mating then the similarity of swelling periods could cause confusion.

During the conception cycle, males concentrated their mating activity around the fertile period, when fertilisation was most likely, suggesting that males may use further cues than absolute swelling size alone to determine when to mate. Male copulation rates gradually increased towards the fertile period and decreased abruptly afterwards (Fig. 3), which is consistent with previous data on semi-free ranging Barbary macaques (Heistermann et al., 2008). Males in several other species also concentrate mating around the fertile period (Aujard et al., 1998; Deschner et al., 2004; Engelhardt et al., 2005; Higham et al., 2009, 2012; O'Neill et al., 2004; Wallen et al., 1984) nevertheless; the exact cues males use to determine the fertile phase varies. Inspection rates greatly decreased in frequency after the fertile phase but were similar in the pre-fertile and fertile phases, although the mean frequency was still greatest during the fertile phase (Fig. 3). This implies that males inspected swellings and the anogenital region in order to gain information about the females' reproductive state, similar to a previous study (Heistermann et al., 2008). Close inspection of the female's anogenital region provides a male with further cues to the probability of ovulation such as fine grained visual changes in swellings size or coloration (Deschner et al., 2003; Möhle et al., 2005) or olfactory cues (Cerda-Molina et al., 2006), to date, however, evidence of olfactory detection in macaques is limited (for review see Dixson, 1998). Our data suggest that males may be able to pick up on further hormonal cues given that the inspection rate increased towards the fertile phase and male mating frequency was better predicted by days of the fertile phase than days of the maximum swelling period. But the precise cues males use to infer this additional information could not be disentangled by this study.

The frequency of female socio-sexual behaviours is known to be related to the concentration of oestrogens; in rhesus macaques' oestrogen rise as ovulation approaches coincide with a rise in frequency of female proceptive behaviours such as approaching, soliciting and presenting (Wallen et al., 1984; Zehr et al., 2000). Similarly, Tonkean macaque (M. tonkeana) females increase the frequency of presenting (Aujard et al., 1998) and long-tailed macaques (M. fascicularis) show more reach back behaviour around the fertile phase (Engelhardt et al., 2005), suggesting that female socio-sexual behaviours parallel the changes in female reproductive state. The increase in frequency of these behaviours may be a cue used by males to determine when to concentrate mating effort and in all three macaque species male mating behaviour reaches its peak around the fertile phase. Female sociosexual behaviour, specifically presenting and copulation call frequency, in our study increased in parallel to male copulation rate, increasing in frequency as the fertile phase approached, peaking during the fertile phase and decreasing afterwards. Our data are thus consistent with the idea that males respond to changes in female behaviour; although which cues males use exactly remains to be investigated.

While males seemed to use these additional cues to concentrate mating around ovulation, all males including the alpha male mated at the same rate during conception and post-conception swelling phases. In addition, male inspection and female presenting frequencies did not differ between these two swelling phases. Similarly, long-tailed macaque copulation rates and female socio-sexual behaviour also remained similar during conception and post-conception periods (Engelhardt et al., 2007). Mating during gestation is not uncommon in macaque species (Engelhardt et al., 2007; Fürtbauer et al., 2011; Nieuwenhuijsen et al., 1986; Wilson et al., 1982) and may be linked to distinct endocrine changes during pregnancy. Both a decrease in progestogen levels in association with a parallel increase in oestrogen concentrations (Wilson et al., 1982) and a resultant increase in the E/P ratio (Bielert et al., 1976; Engelhardt et al., 2007) are known to coincide with increased mating frequencies during gestation. As the increase in size of the swelling and change in $\mathrm{E} / \mathrm{P}$ ratio occur during both conception and post-conception swelling periods it is difficult to tease apart which, if any, cue males use for deciding if and when to mate. Whether these additional swellings have an adaptive function or not is uncertain (reviewed by Engelhardt et al., 2007) but indirectly they are costly to males, who invest time and energy in vain. Post-conception swellings can enhance promiscuity by adding another mating cycle to the reproductive phase of a female.

Across primates female reproductive synchrony is the main determinant of male monopolisation potential and consequently reproductive skew (Ostner et al., 2008). By producing a post-conception swelling female Barbary macaques in this study increased reproductive synchrony by $25 \%$ (from $32 \%$ overlap (excluding post-conception cycles) to $40 \%$, Young et al. unpubl. data) effectively reducing male monopolisation potential and possibly enhancing paternity confusion. Whether post-conception swellings are a further development in the inter-sexual arms race between males and females to maximise female reproductive potential and limit the information available to males (van Schaik et al., 2004) or a purely by-product of changes in hormonal concentrations needs further studies.

Taken together, our study provides new insights into the information available to males, namely female socio-sexual behaviour, hormonal cues and sexual swellings and how males "respond" to them in terms of allocating their copulatory activity. Perhaps most interestingly, our results raise intriguing questions about the underlying mechanisms and function of post-conception swellings, which were beyond the scope of this study. Future studies examining mating behaviour during gestation swelling periods form both a male and female perspective could shed light on a possible adaptive or mechanistic function of these swellings. Females with additional conspicuous swellings could endure costs in terms of energy expenditure during pregnancy and increased behavioural and time constraints imposed by greater attractiveness to males. Detailed evaluation of changes in female hormone concentrations, in particular the E/P ratio and fine-grade changes in swelling size during post-conception swelling periods may enhance our understanding of the underlying mechanisms of these swelling periods. If males do follow fine-scale changes in swelling size or infer information from changes in hormonal concentrations as to when to mate this would, in multi-male 
multi-female groups over a mating season, require males to monitor changes of all females over time within the group. Whether, over several months, cercopithecine primate males have the cognitive abilities required to maintain such detailed information would require further research. By considering primate sexual behaviour outside periods surrounding fertility future research into the evolution of female sexual signals may be enhanced.

\section{Acknowledgments}

The authors are grateful to Professor Mohamed Qarro (Ecole Nationale Forestière d'Ingénieurs, Morocco) for his support in the field and the Haut Commissariat aux Eaux et Forêts et à la Lutte Contre la Désertification of Morocco for research permission. We would also like to thank Michael Madole, Dave Thomas, Sofia Santos, Maria Thunström, Tom Smith and Josephine Msindai for assistance in the field and Ines Fürtbauer and Laëtitia Maréchal for helpful comments. We would also like to thank Andrea Heistermann and Petra Kiesel for providing assistance and expertise during hormone analysis. Furthermore, we would like to thank Dr. Kim Wallen and two anonymous referees for useful comments to significantly improve the manuscript. Financial support was provided by the Max Planck Society, the Christian Vogel Fonds and the Georg-August University Göttingen through funds from the German Initiative of Excellence. This study complies with Moroccan, German and UK regulations regarding the ethical treatment of research subjects.

\section{References}

Altmann, J., 1974. Observational study of behavior: sampling methods. Behavior 49, 227-267.

Aujard, F., Heistermann, M., Thierry, B., Hodges, J.K., 1998. Functional significance of behavioral, morphological and endocrine correlates across the ovarian cycle in semi free-ranging female Tonkean macaques. Am. J. Primatol. 46, 285-309.

Baayen, H.R., 2008. Analyzing Linguistic Data. A Practical Introduction to Statistics Using R. Cambridge University Press.

Barelli, C., Heistermann, M., Boesch, C., Reichard, U.H., 2008. Mating patterns and sexual swellings in pair-living and multimale groups of wild white-handed gibbons, Hylobates lar. Anim. Behav. 75, 991-1001.

Bates, D., Maechler, M., 2010. Ime4: Linear Mixed-effects Models Using S4 Classes. R Package Version 0.999375-37.

Behboodi, E., Katz, D.F., Samuels, S.J., Tell, L., Hendrickx, A.G., Lasley, B.L., 1991. The use of a urinary estrone conjugates assay for detection of optimal mating time in the cynomolgus macaque (Macaca fascicularis). J. Med. Primatol. 20, 229-234.

Bielert, C., Anderson, C.M., 1985. Baboon sexual swellings and male response: a possible operational mammalian supernormal stimulus and response mechanism. Int. J. Primatol. 6, 377-393.

Bielert, C., Czaja, J.A., Eisele, S., Scheffler, G., Robinson, J.A., Goy, R.W., 1976. Mating in the rhesus monkey (Macaca mulatta) after conception and its relationship to oestradiol and progesterone levels throughout pregnancy. J. Reprod. Fertil. 46, 179-187.

Brauch, K., Pfefferle, D., Hodges, K., Möhle, U., Fischer, J., Heistermann, M., 2007. Female sexual behavior and sexual swelling size as potential cues for males to discern the female fertile phase in free-ranging Barbary macaques (Macaca sylvanus) of Gibraltar. Horm. Behav. 52, 375-383.

Carnegie, S.D., Fedigan, L.M., Ziegler, T.E., 2005. Behavioral indicators of ovarian phase in white-faced capuchins (Cebus capucinus). Am. J. Primatol. 67, 51-68.

Cerda-Molina, A., Hernandez-Lopez, L., Chavira, R., Cardenas, M., Paez-Ponce, D., Cervantes-De la Luz, H., Mondragon-Ceballos, R., 2006. Endocrine changes in male stumptailed macaques (Macaca arctoides) as a response to odour stimulation with vaginal secretions. Horm. Behav. 49, 81-87.

de Vries, H., Stevens, J., Vervaecke, H., 2006. Measuring and testing the steepness of dominance hierarchies. Anim. Behav. 71, 585-592.

Deag, J.M., 1974. A study of the social behaviour and ecology of the wild Barbary macaque Macaca sylvanus. PhD thesis, University of Bristol, Bristol, UK.

Deschner, T., Heistermann, M., Hodges, J., Boesch, C., 2003. Timing and probability of ovulation in relation to sex skin swelling in wild West African chimpanzees, Pan troglodytes verus. Anim. Behav. 66, 551-560.

Deschner, T., Heistermann, M., Hodges, J.K., Boesch, C., 2004. Female sexual swelling size, timing of ovulation, and male behavior in wild West African chimpanzees. Horm. Behav. 46, 204-215.

R Development Core Team, 2011. R: A Language and Environment for Statistical Computing. R Foundation for Statistical Computing, Vienna, Austria.

Dixson, A.F., 1998. Primate Sexuality. Oxford University Press, Oxford.

Dubuc, C., Muniz, L., Heistermann, M., Engelhardt, A., Widdig, A., 2011. Testing the priority-of-access model in a seasonally breeding primate species. Behav. Ecol. Sociobiol. 65, 1615-1627.
Emery, M., Whitten, P., 2003. Size of sexual swellings reflects ovarian function in chimpanzees (Pan troglodytes). Behav. Ecol. Sociobiol. 54, 340-351.

Engelhardt, A., Pfeifer, J.-B., Heistermann, M., Niemitz, C., van Hooff, J., Hodges, J., 2004 Assessment of female reproductive status by male long-tailed macaques, Macaca fascicularis, under natural conditions. Anim. Behav. 67, 915-924.

Engelhardt, A., Hodges, J.K., Niemitz, C., Heistermann, M., 2005. Female sexual behavior but not sex skin swelling reliably indicates the timing of the fertile phase in wild long-tailed macaques (Macaca fascicularis). Horm. Behav. 47, 195-204.

Engelhardt, A., Hodges, J., Heistermann, M., 2007. Post-conception mating in wild longtailed macaques (Macaca fascicularis): characterization, endocrine correlates and functional significance. Horm. Behav. 51, 3-10.

Fürtbauer, I., Heistermann, M., Schülke, O., Ostner, J., 2011. Concealed fertility and extended female sexuality in a non-human primate (Macaca assamensis). PLoS One 6, e23105.

Gordon, T., Gust, D., Busse, C., Wilson, M., 1991. Hormones and sexual behavior associate with post-conception perineal swelling in the sooty mangabey (Cercocebus torquatus atys). Int. J. Primatol. 12, 585-597.

Gust, D., 1994. Alpha-male sooty mangabeys differentiate between females' fertile and their post-conception maximal swellings. Int. J. Primatol. 15, 289-301.

Heistermann, M., Finke, M., Hodges, J.K., 1995. Assessment of female reproductive status in captive-housed Hanuman langurs (Presbytis entellus) by measurement of urinary and fecal steroid excretion patterns. Am. J. Primatol. 37, 275-284.

Heistermann, M., Möhle, U., Vervaecke, H., van Elsacker, L., Hodges, J.K., 1996. Application of urinary and fecal steroid measurements for monitoring ovarian function and pregnancy in the Bonobo (Pan paniscus) and evaluation of perineal swelling patterns in relation to endocrine events. Biol. Reprod. 55, 844-853.

Heistermann, M., Brauch, K., Möhle, U., Pfefferle, D., Dittami, J., Hodges, K., 2008. Female ovarian cycle phase affects the timing of male sexual activity in free-ranging Barbary macaques (Macaca sylvanus) of Gibraltar. Am. J. Primatol. 70, 44-53.

Higham, J.P., Heistermann, M., Ross, C., Semple, S., MacLarnon, A., 2008a. The timing of ovulation with respect to sexual swelling detumescence in wild olive baboons. Primates 49, 295-299.

Higham, J.P., MacLarnon, A.M., Ross, C., Heistermann, M., Semple, S., 2008b. Baboon sexual swellings: information content of size and color. Horm. Behav. 53, 452-462.

Higham, J.P., Semple, S., MacLarnon, A., Heistermann, M., Ross, C., 2009. Female reproductive signaling, and male mating behavior, in the olive baboon. Horm. Behav. 55, 60-67.

Higham, J.P., Heistermann, M., Saggau, C., Agil, M., Perwitasari-Farajallah, D. Engelhardt, A., 2012. Sexual signalling in female crested macaques and the evolution of primate fertility signals. BMC Evol. Biol. 12, 89.

Hodges, J.K., Heistermann, M., Beard, A., van Aerde, R.J., 1997. Concentrations of progesterone and the $5 \alpha$-reduced progestins, $5 \alpha$-pregnane-3, 20-dione and $5 \alpha$ pregnane- $3 \alpha$-ol-20-one in luteal tissue and circulating blood and their relationship to luteal function in the African elephant, Loxodonta africana. Biol. Reprod. $56,640-646$.

Hrdy, S.B., Whitten, P.L., 1987. Patterning of sexual activity. In: Smuts, B.B., Cheney, D.L. Seyfarth, R.M., Wrangham, R.W., Struhsaker, T.T. (Eds.), Primate Societies. The University of Chicago Press, Chicago, pp. 370-384.

Küster, J., Paul, A., 1984. Female reproductive characteristics in semi free-ranging Barbary Macaques (Macaca sylvanus L. 1758). Folia Primatol. 43, 69-83.

Leiva, D., de Vries, H., 2011. Testing Steepness of Dominance Hierarchies. R Package Version 0.2

Lisk, R.D., Ciaccio, L.A., Catanzaro, C., 1983. Mating behaviour of the golden hamster under semi-natural conditions. Anim. Behav. 31, 659-666.

Lu, A., Beehner, J.C., Czekala, N.M., Borries, C., 2012. Juggling priorities: female mating tactics in Phayre's leaf monkeys. Am. J. Primatol. 74, 471-481.

McCarthy, M., Becker, J., 2002. Neuroendocrinology of sexual behavior in the female. In: Becker, J., et al. (Ed.), Behavioral Endocrinology. The MIT Press, Cambridge pp. 117-152.

Möhle, U., Heistermann, M., Dittami, J., Reinberg, V., Hodges, J., 2005. Patterns of anogenital swelling size and their endocrine correlates during ovulatory cycles and early pregnancy in free-ranging Barbary macaques (Macaca sylvanus) of Gibraltar. Am. J. Primatol. 66, 351-368.

Nieuwenhuijsen, K., De Neef, K., Slob, A., 1986. Sexual behaviour during ovarian cycles, pregnancy and lactation in group-living stumptail macaques (Macaca arctoides). Hum. Reprod. 1, 159-169.

Nunn, C.L., 1999. The number of males in primate groups: a comparative test of the socioecological model. Behav. Ecol. Sociobiol. 46, 1-13.

Nunn, C.L., Altizer, S.M., 2004. Sexual selection, behaviour and sexually transmitted diseases. In: Kappeler, P.M., van Schaik, C.P. (Eds.), Sexual Selection in Primates: New and Comparative Perspectives. Cambridge University Press, Cambridge, pp. 117-130.

Nunn, C.L., van Schaik, C.P., Zinner, D., 2001. Do exaggerated sexual swellings function in female mating competition in primates? A comparative test of the reliable indicator hypothesis. Behav. Ecol. 12, 646-654.

O'Neill, A., Fedigan, L.M., Ziegler, T.E., 2004. Ovarian cycle phase and same-sex mating behavior in Japanese macaque females. Am. J. Primatol. 63, 25-31.

Ostner, J., Chalise, M., Koenig, A., Launhardt, K., Nikolei, J., Podzuweit, D., Borries, C., 2006. What Hanuman langur males know about female reproductive status. Am. J. Primatol. 68, 701-712.

Ostner, J., Nunn, C.L., Schülke, O., 2008. Female reproductive synchrony predicts skewed paternity across primates. Behav. Ecol. 19, 1150-1158.

Rasmussen, L.E.L., Schulte, B.A., 1998. Chemical signals in the reproduction of Asian (Elephas maximus) and African (Loxodonta africana) elephants. Anim. Reprod. Sci. 53, 19-34.

Reichert, K.E., Heistermann, M., Hodges, J.K., Boesch, C., Hohmann, G., 2002. What females tell males about their reproductive status: are morphological and 
behavioural cues reliable signals of ovulation in bonobos (Pan paniscus)? Ethology $108,583-600$.

Semple, S., 1998. The function of Barbary macaque copulation calls. Proc. R. Soc. Lond. B 265, 287-291.

Setchell, J., Charpentier, M., Wickings, E., 2005. Mate guarding and paternity in mandrills: factors influencing alpha male monopoly. Anim. Behav. 70, 1105-1120.

Shelmidine, N., Borries, C., Koenig, A., 2007. Genital swellings in silvered langurs: what do they indicate? Am. J. Primatol. 69, 519-532.

Sherman, P.W., 1989. Mate guarding as paternity insurance in Idaho ground squirrels Nature 338, 418-420.

Shideler, S.E., Ortuño, A.M., Morán, F.M., Moorman, E.A., Lasley, B.L., 1993. Simple extraction and enzyme immunoassays for estrogen and progesterone metabolites in the feces of Macaca fascicularis during non-conceptive and conceptive ovarian cycles. Biol. Reprod. 48, 1290-1298.

Swaisgood, R.R., Lindburg, D.G., Zhang, H., 2002. Discrimination of oestrous status in Giant pandas (Ailuropoda melanoleuca) via chemical cues in urine. J. Zool. 257, 381-386.

van Schaik, C., Hodges, J., Nunn, C., 2000. Paternity confusion and the ovarian cycles of female primates. In: van Schaik, C., Janson, C. (Eds.), Infanticide by Males and Its Implications. Cambridge University Press, Cambridge, pp. 361-387. van Schaik, C.P., Pradhan, G.R., van Noordwijk, M.A., 2004. Mating conflict in primates: infanticide, sexual harassment and female sexuality. In: Kappeler, P.M., van Schaik, C.P. (Eds.), Sexual Selection in Primates: New and Comparative Perspectives. Cambridge University Press, Cambridge, pp. 131-150.

Wallen, K., 2001. Sex and context: hormones and primate sexual motivation. Horm. Behav. 40, 339-357.

Wallen, K., Winston, L.A., Gaventa, S., Davis-DaSilva, M., Collins, D.C., 1984. Periovulatory changes in female sexual behavior and patterns of ovarian steroid secretion in group-living rhesus monkeys. Horm. Behav. 18, 431-450.

Westlin, L.M., 1996. Behavioural manifestation of conception 12 hours after mating in an asocial African rodent, Saccostomus campestris. J. Zool. 239, 515-523.

Wilcox, A.J., Weinberg, C.R., Baird, D.D., 1995. Timing of sexual intercourse in relation to ovulation. N. Engl. J. Med. 333, 1517-1521.

Wilson, M.E., Gordon, T.P., Collins, D.C., 1982. Serum 17ß-estradiol and progesterone associated with mating behavior during early pregnancy in female rhesus monkeys. Horm. Behav. 16, 94-106.

Zehr, J.L., Maestripieri, D., Wallen, K., 1998. Estradiol increases female sexual initiation independent of male responsiveness in rhesus monkeys. Horm. Behav. 33, 95-103.

Zehr, J.L., Tannenbaum, P.L., Jones, B., Wallen, K., 2000. Peak occurrence of female sexual initiation predicts day of conception in rhesus monkeys (Macaca mulatta). Reprod. Fertil. Dev. 12, 397-404. 